\title{
Traffic calming measures and their effect on the variation of speed
}

\author{
Hernán Gonzalo-Orden \\ Professor, University of Burgos, Spain \\ Marta Rojo \\ Assistant Professor, University of Burgos, Spain \\ Heriberto Pérez-Acebo \\ Assistant Professor, University of the Basque Country, Spain
}

Alaitz Linares

Researcher, University of Burgos, Spain

\section{SUMMARY}

In recent years the number of deaths and serious injuries is decreasing in Spain, but, although the reduction outside the cities has been very strong, inside the urban areas, it has been smaller. This is especially hard if you look at the most vulnerable road users such as pedestrians and cyclists. In many accidents the speed factor appears closely linked not only to the number, but also to the severity of the accidents suffered inside the urban areas. Therefore, a reduction in the speed would improve the road safety.

There are different measures known as "traffic calming measures" whose objectives are to reduce both the number and severity of accidents that occur on urban areas, by reducing the traffic flow through the streets, as well as the speed of the vehicles. However, the efficiency in speed reduction of each measure is not entirely known. That's the reason why they are implanted, in many cases, with no technical basis.

The aim of this article is to show the effectiveness in reducing speed of some of the traffic calming measures. To this effect, field measurements were done on street sections with different types of traffic calming measures, in different places of a city of Burgos, in the north of Spain. These measurements were compared with other ones sited on other streets sections of similar characteristics but without traffic calming measures.

Finally the conclusions are shown and some recommendations for improving their effectiveness are given.

\section{INTRODUCTION}

The road safety is a major problem all over the world. Just in the roads of the European Union, during 2009, more than 35,000 people died and more than 1,500,000 were injured. The cost of those accidents for society is huge and it is estimated on approximately 130 billion Euros (EC, 2010).

In Spain, during 2014, 1,688 people died and 9,574 were seriously injured. 25 years ago, in 
1989, the fatalities were much higher reaching 9,344 deaths. Among the fatalities on 2014, 1,247 occurred outside urban areas and 441 inside urban areas. If we look back to 2005, 3,652 people died outside urban areas and 790 inside urban areas. It has been a great improvement but the reductions outside urban areas $(66 \%)$ had been higher than inside urban areas (44\%) (DGT, 2015a).

To improve the safety inside urban areas the European Commission (EC) presented in 2010 the communication: Towards a European road safety area: policy orientations on road safety 2011-2020. COM (2010) 389 final. The objective $\mathrm{n}^{\circ} 7$ is Protect vulnerable road users such as motorcycle riders, mopeds, cyclist and pedestrians. The EC was worried because the high number of fatalities and serious injured were significant and in some European States were still increasing (EC, 2010).

In Spain, in 2014, 192 pedestrians died over the total of 441 fatalities inside urban areas. To reduce the high number of fatalities and serious injuries many countries are using the traffic calming strategies.

The subcommittee of the Institute of Transportation Engineering define traffic calming as:

"Traffic calming is the combination of mainly physical measures that reduce the negative effects of motor vehicle use, alter driver behavior and improve conditions for non-motorized street users" (Lockwood, 1997).

Basically traffic calming strategies designed to reduce vehicle speeds and volumes that drive thought an area. Some of these strategies and devices used are: Vehicle restrictions, warning signs, gateways, speed tables, raised crosswalks, median islands, channelization islands, speed humps, rumble strips, mini-circles, roundabouts, special pavements and markings, radar clocked traffic speeds displayed to drivers, lane narrowing, horizontal shifts...

The reduction of the motor vehicles speeds is one of the key elements to reduce the probability of death of the pedestrians involved in the accident. Therefore, this article analyzes the impact of Traffics calming measures on the reduction of the motor vehicles speed.

\begin{tabular}{|c|c|c|c|c|}
\hline Speed of collision $(\mathrm{km} / \mathrm{h})$ & 80 & 60 & 40 & 20 \\
\hline Probability of death $(\%)$ & 100 & 85 & 30 & 10 \\
\hline
\end{tabular}

Fig. 5 - Relationship between the speed of the vehicle and the the probability of death of the pedestrian involved in the accident (Bonanomi, 1990).

After this chapter, Chapter 2 shows the methodology and the case of study. Results and discussions are shown in Chapter 3 and Chapter 4 includes the main findings of the study.

2. METHODOLOGY AND CASE OF STUDYTo show the effectiveness in reducing 
speed of some of the traffic calming measures field measurements were done on various calmed traffic street sections of Burgos (Medium-sized city, 170.000 inhabitants, situated in the North-central part of Spain). These measurements were compared with the ones taken on other urban streets of similar characteristics but without traffic calming measures. The maximum speed allowed in the city is $50 \mathrm{Km} / \mathrm{h}$. In some of the traffic calmed sections the maximum speed is $30 \mathrm{Km} / \mathrm{h}$.

An inventory of traffic calming measures was done and more than 100 measures implanted were found. From this inventory six representative zones were selected. The vehicle speeds on the street sections ( $\mathrm{StS}$ ) inside traffic calm areas were controlled with speed radars and compared with the ones taken on other streets without the traffic calming measures.

22 street sections, distributed on these six zones of the city, were analyzed. A basic description of these zones is given in the following lines. Each zone must have at least one of the traffic calming measures inside and must begin in an intersection regulated by a roundabout, a traffic light or a stop sign. In this zones it can be found:

- Intersection regulated by a roundabout (I-RB), by a Traffic signal (I-T) and by a Stop sign (I-STOP).

- Normal Crosswalk (CW), Raised Crosswalk (RCW) and Crosswalk with pedestrian pushbutton traffic signal (CW-T).

- Speed warning signs: SWS-30. There is 2 of them indicating than the maximum speed, in the zone between them, is $30 \mathrm{~km} / \mathrm{h}$.

- Radar speed camera (RSC-50). If the car circulates in front of the camera at more than 50 $\mathrm{Km} / \mathrm{h}$ the owner of the car could get a speed violation fine.

- Radar speed camera sign (RSCs-50). Indicates that in the following meters there is a RSC50.

- Lane narrowing: LN.
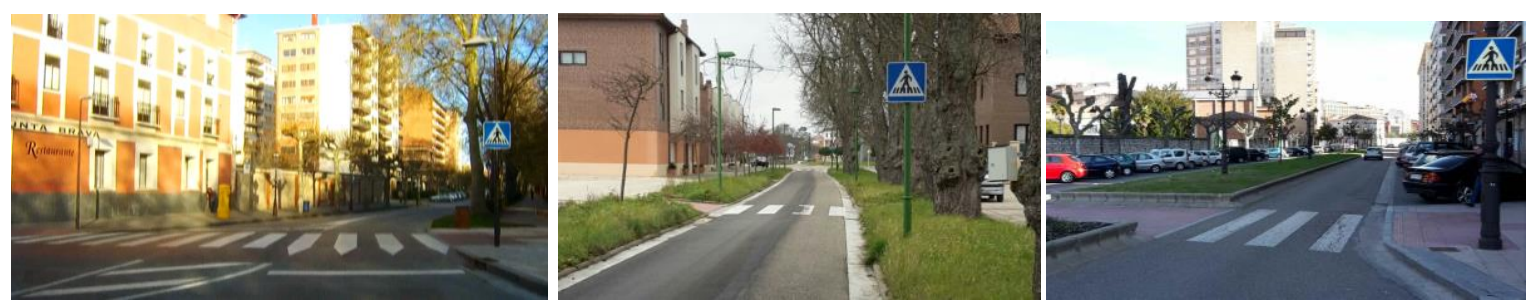

Fig. 1 - Raised Crosswalk

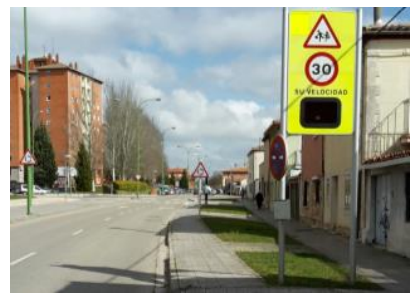

Fig. 4 - Speed warning signs 2.1 Zone 1

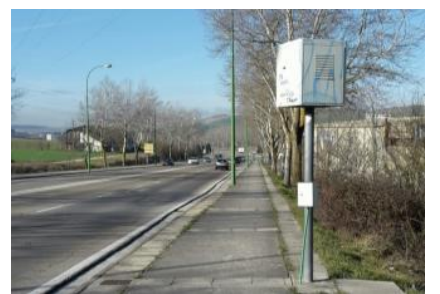

Fig. 5 - Radar speed camera Fig. 6 - Radar speed camera sign

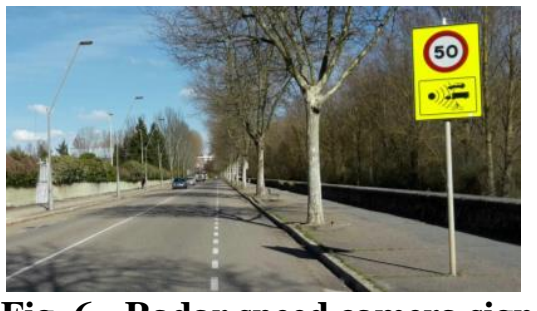


This zone (Fig. 7) follows the street Paseo de la Isla between the intersection with the street Calle León and the roundabout of Plaza Castilla. This street runs along the riverside of the river Arlanzón. In the other riverside there is the street of Avenida Palencia.

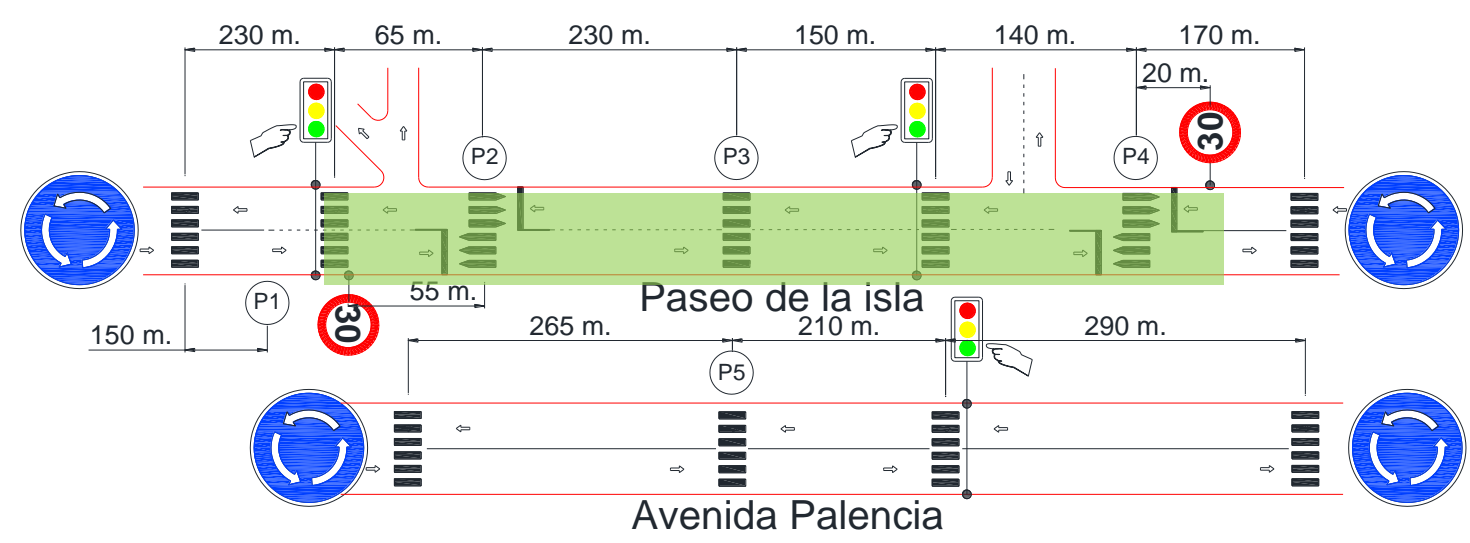

Fig. 7 -Zone 1 analyzed.

\subsection{Zone 2}

This zone (fig. 8) is located in the street Calle Pozanos The main traffic calming measures are 2 School speed warning signs (SWS-30) with a roundabout between them.

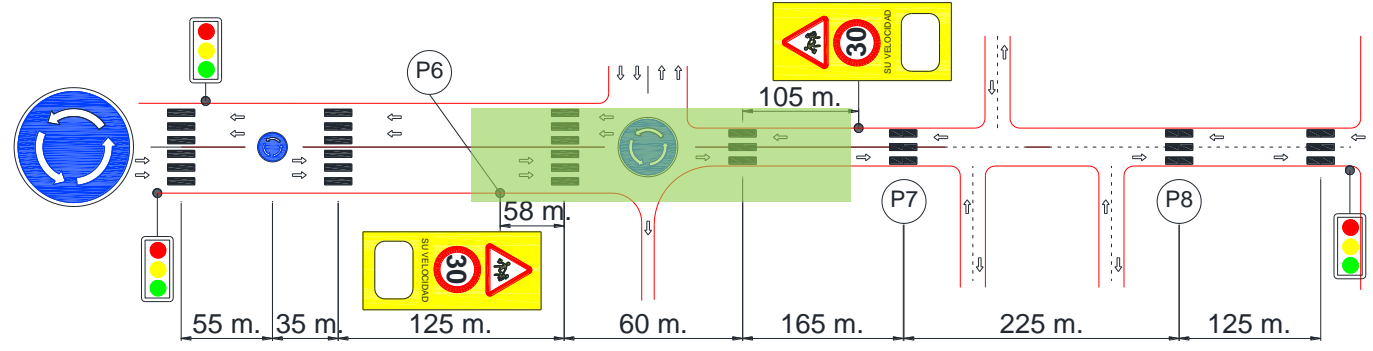

Fig. 8 -Zone 2 analyzed.

\subsection{Zone 3}

This zone (Fig. 9) follows the street Avenida Costa Rica between the roundabout with street Calle Modesto Ciruelos and the roundabout with street Calle Albacastro. In the street Avenida Costa Rica there are located two School speed warning signs (SWS-30) and a lane narrowing (Fig. 2). Almost parallel to this street runs the street Calle Modesto Ciruelos between two roundabouts.

\subsection{Zone 4.}

This zone (Fig 10) follows the street Calle del Carmen (Fig. 3). The whole street was narrowed with elevated median islands. Perpendicular to the street Calle del Carmen run the street Calle Dr. José Luis Santamaría.

\subsection{Zone 5 and 6.}

These two zones have Radar speed cameras. Zone 5 is located in the street Avenida del Cementerio (four lanes. Fig. 5 and Fig 11) and the second is located in the street Avenida Arlanzón (Fig. 12). 


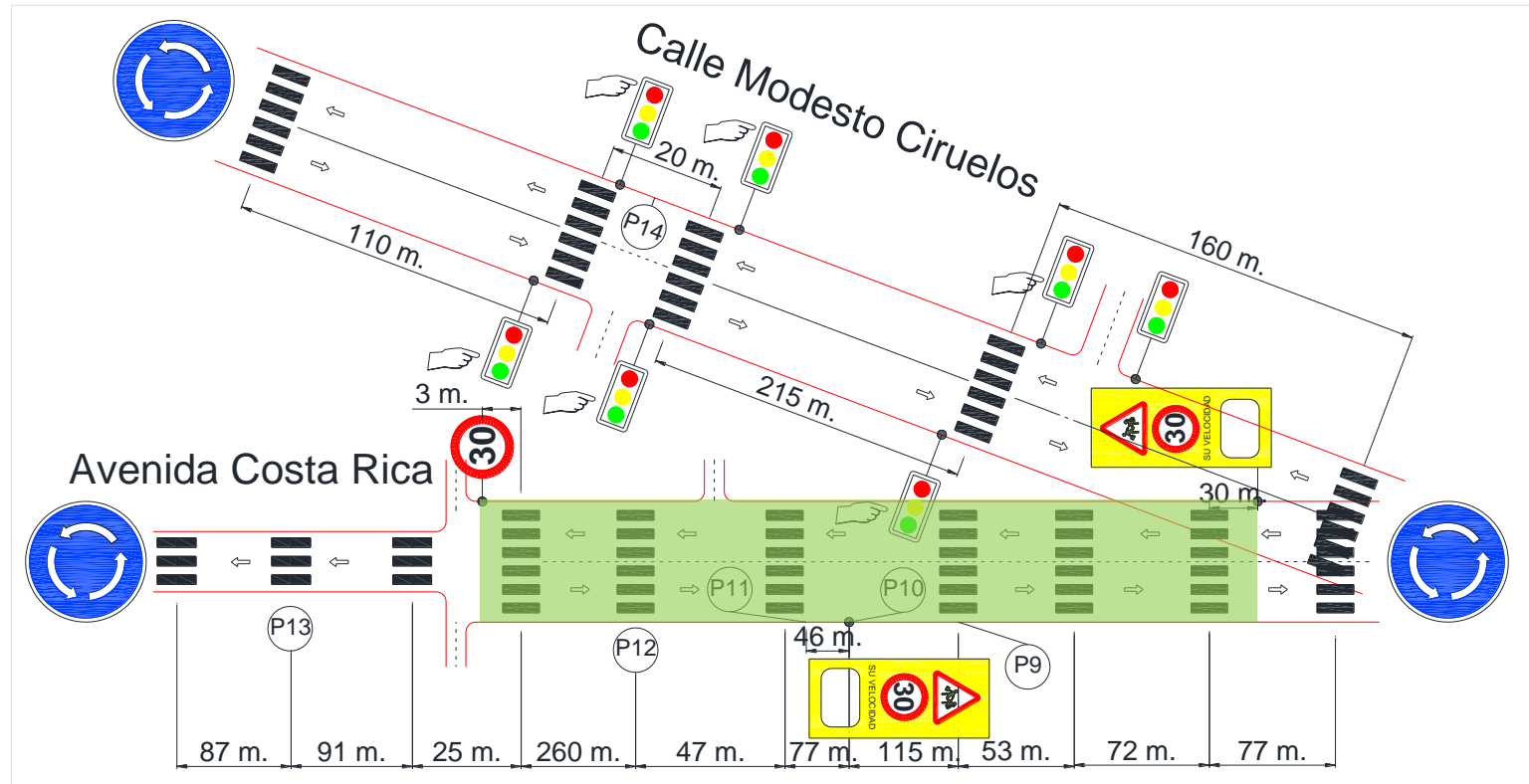

Fig. 9 -Zone 3 analyzed.

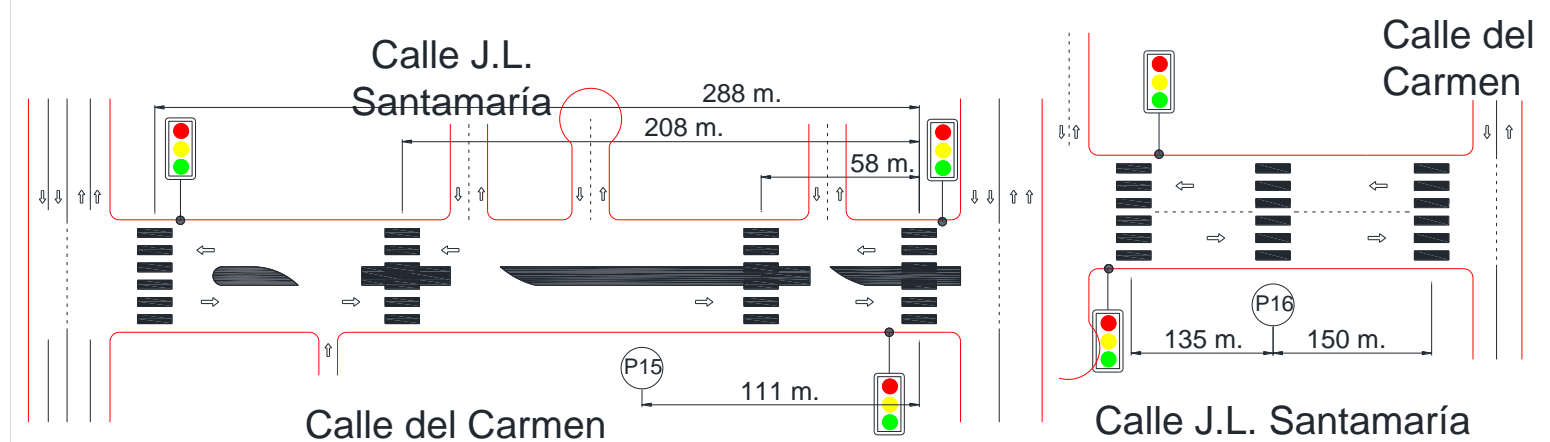

Fig. 10 -Zone 4 analyzed.

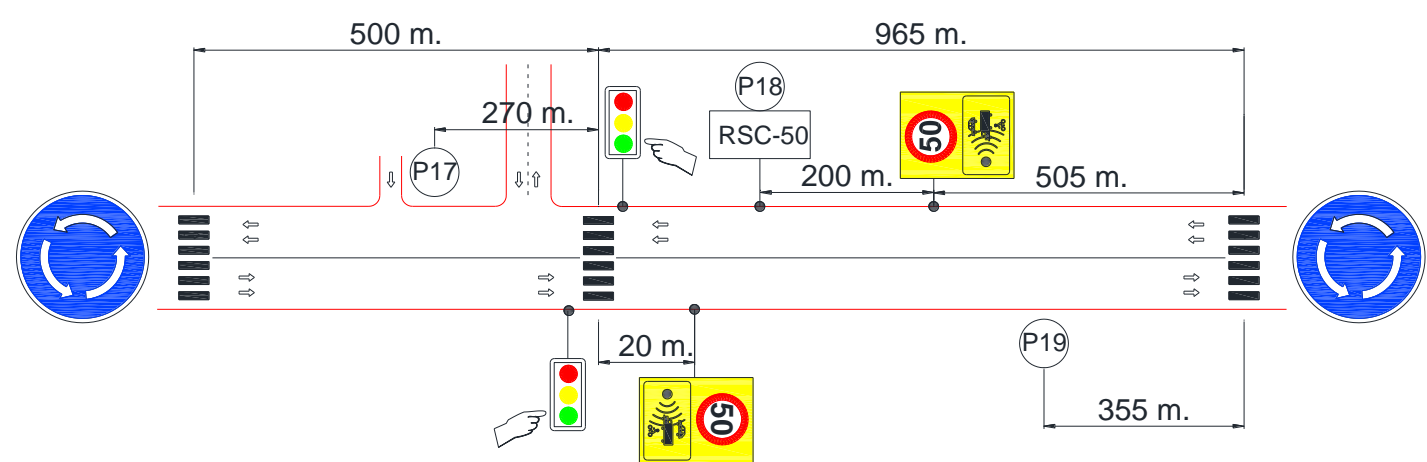

Fig. 11 -Zone 5 analyzed.

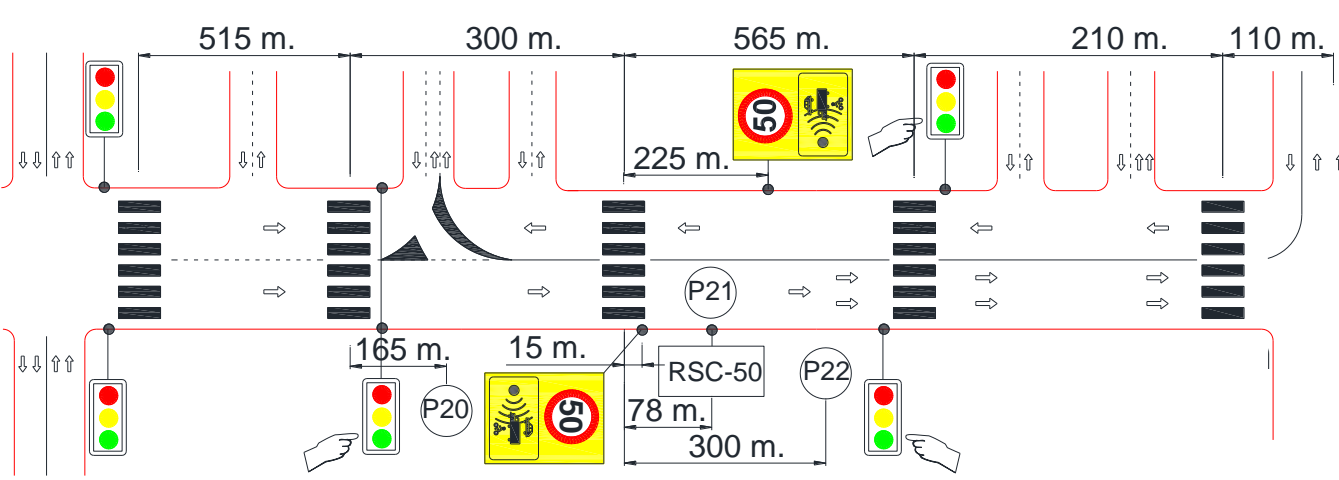

Fig. 12 -Zones 6 analyzed. 


\section{RESULTS AND DISCUSSIONS}

Over ten thousand vehicles were controlled on the 22 street sections (StS). In the following table the speed $\mathrm{V}_{50}$ (is the speed achieved or exceeded by $50 \%$ of the vehicles), the speed $\mathrm{V}_{85}$ (is the speed not reached by $85 \%$ of vehicles or the speed achieved or exceeded by $15 \%$ of vehicles) and the traffic flow are shown.

\begin{tabular}{|c|c|c|c|c|c|c|c|c|c|c|c|c|c|c|c|c|c|c|c|c|c|c|}
\hline Zone & \multicolumn{3}{|c|}{ 1 } & \multicolumn{3}{|c|}{$\mathbf{2}$} & \multicolumn{5}{|c|}{$\mathbf{3}$} & \multicolumn{5}{|c|}{$\mathbf{5}$} & \multicolumn{3}{c|}{$\mathbf{6}$} \\
\hline $\begin{array}{c}\text { Point of } \\
\text { measure }\end{array}$ & P1 & P2 & P3 & P4 & P5 & P6 & P7 & P8 & P9 & P10 & P11 & P12 & P13 & P14 & P15 & P16 & P17 & P18 & P19 & P20 & P21 & P22 \\
\hline $\begin{array}{c}\text { Speed V50 } \\
\text { (km/h) }\end{array}$ & 36 & 34 & 45 & 37 & 55 & 43 & 42 & 38 & 42 & 46 & 41 & 44 & 42 & 56 & 29 & 40 & 59 & 46 & 55 & 48 & 44 & 50 \\
\hline $\begin{array}{c}\text { Speed V85 } \\
\text { (Km/h) }\end{array}$ & 46 & 41 & 55 & 43 & 64 & 50 & 50 & 52 & 51 & 55 & 53 & 55 & 52 & 67 & 39 & 50 & 71 & 52 & 65 & 59 & 50 & 61 \\
\hline $\begin{array}{c}\text { Traffic flow } \\
\text { (Veh/h) }\end{array}$ & 349 & 324 & 430 & 595 & 604 & 503 & 753 & 527 & 103 & 92 & 71 & 72 & 20 & 240 & 460 & 251 & 1326 & 1195 & 1232 & 360 & 416 & 398 \\
\hline
\end{tabular}

Table 1 - Speed of vehicles controlled on the twenty two street sections

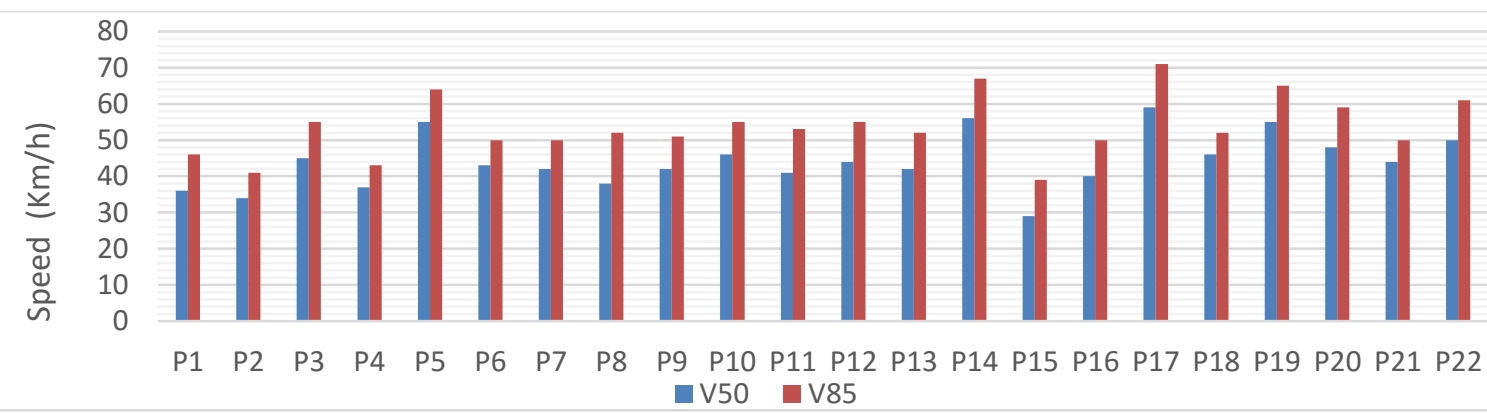

Fig. $13-V_{50}$ and $V_{85}$ speed measured at the 22 street sections

\subsection{Raised Crosswalks at zone 1}

In zone 1 their Raised Crosswalks (P2 and P4), inside of the zones with traffic calming measures (in-TCZ), present a $\mathrm{V}_{50}$ and $\mathrm{V}_{85}$ speeds $20 \mathrm{~km} / \mathrm{h}$ lower than in the crosswalks outside of the zones with traffic calming measures (out-TCZ) (P5). The speed profiles of the 2 raised Crosswalks are similar (P2 and P4). In the normal crosswalk in-TCZ (P3) the speeds were almost $10 \mathrm{~km} / \mathrm{h}$ lower than out-TCZ. P1 presents a similar speed to the raised crosswalks of that zone influenced by the roundabout at the beginning of the street (at 150 m) and by the Raised Crosswalk P2 (at 145 m). Pau and Angius, (2001) indicate the existence of an influence region ranging from 30 to $60 \mathrm{~m}$ for the "speed bumps". Here it can be seen that at $145 \mathrm{~m}$ there is still some influence. The fig. 14 shows that the objective of maintaining the $\mathrm{V}_{85}$ lower than $30 \mathrm{Km} / \mathrm{h}$ between $\mathrm{P} 2$ and $\mathrm{P} 4$ has not been achieved.

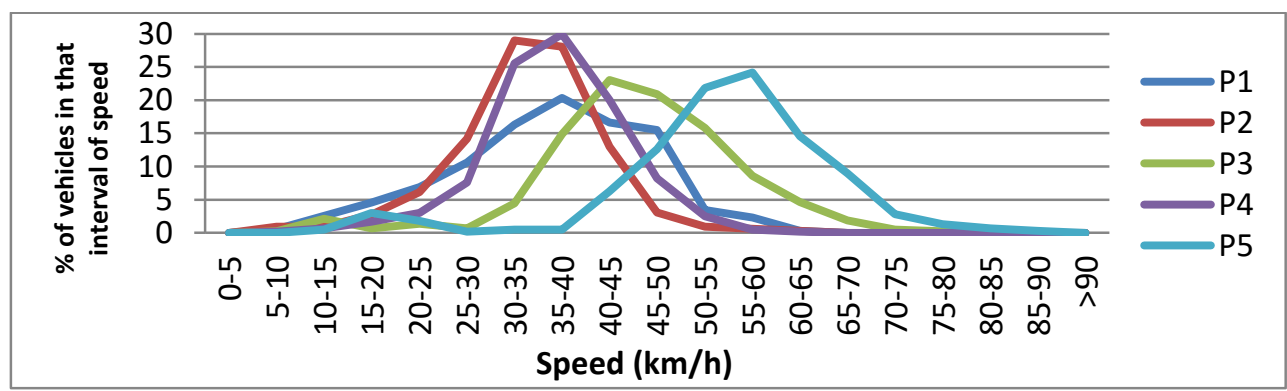

Fig. 14 - Speed profile at zone 1

This work is licensed under a Creative Commons Attribution-NonCommercial-NoDerivatives 4.0 International License (CC BY-NCND 4.0). 


\subsection{Speed warning signs at zones 2 and 3}

In zone 2 and zone 3 the street sections (P6 - P7 and P9 - P12) between the two Speed warning signs (SWS-30) present a $\mathrm{V}_{85}$ speed $10-15 \mathrm{~km} / \mathrm{h}$ lower than the speed of the zones out-TCZ (P5 and P14) (Fig. 14 and 15). The Street section at P8 presents similar speed to the P6 and P7 influenced by the P7 and the end of the street. The fig. 15 shows that the objective of maintaining the $\mathrm{V}_{85}$ lower than $30 \mathrm{Km} / \mathrm{h}$ between sections P6 - P7 and P9 - P12 has not been achieved. These measures should be combined with other traffic calming actions to increase the effectiveness of speed reduction.

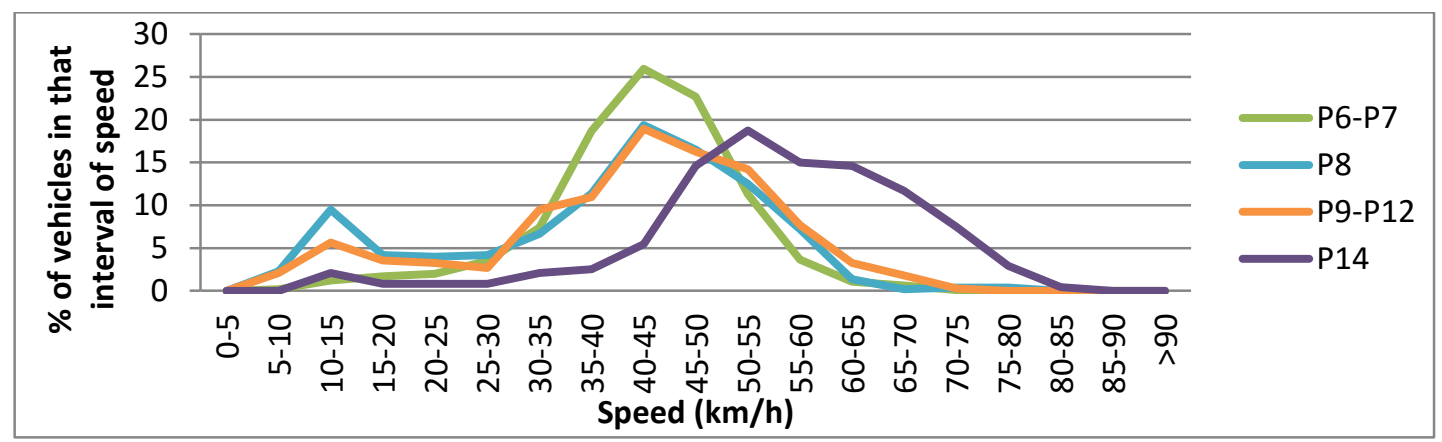

Fig. 15 - Speed profile at zones 2 and 3

\subsection{Lane narrowing at zones 3 and 4}

In zone 3 the lane narrowing (LN) at P13 doesn't work as good as the LN of the zone 4 (P15). It can be seen that in the $\mathrm{LN}$ (P13) the $\mathrm{V}_{50}$ and $\mathrm{V}_{85}$ speeds are around $15 \mathrm{~km} / \mathrm{h}$ lower than in the P14. In zone 4 the speed reduction is around $10 \mathrm{~km} / \mathrm{h}$ (P15 and P16). The LN with the construction of elevated median islands seems to help in the speed reduction.

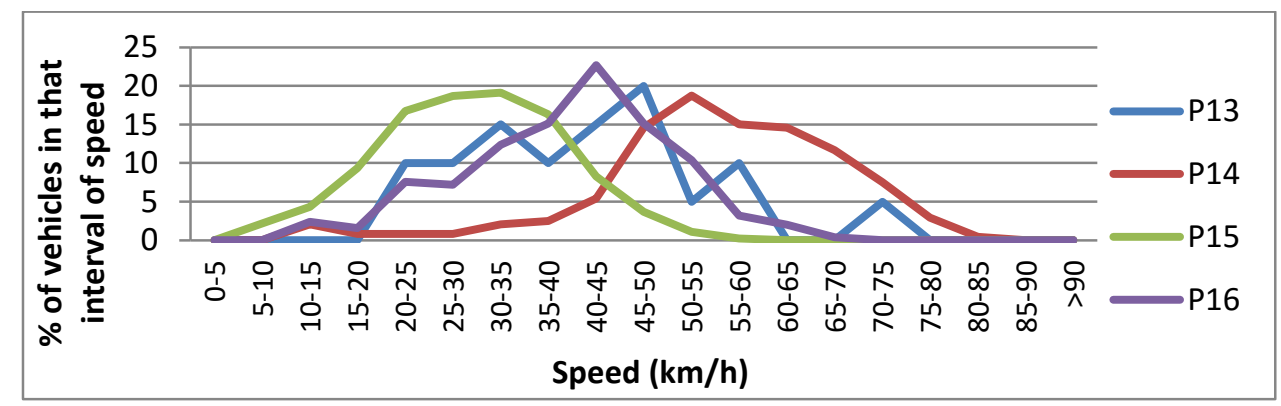

Fig. 16 - Speed profile at zones 3 and 4

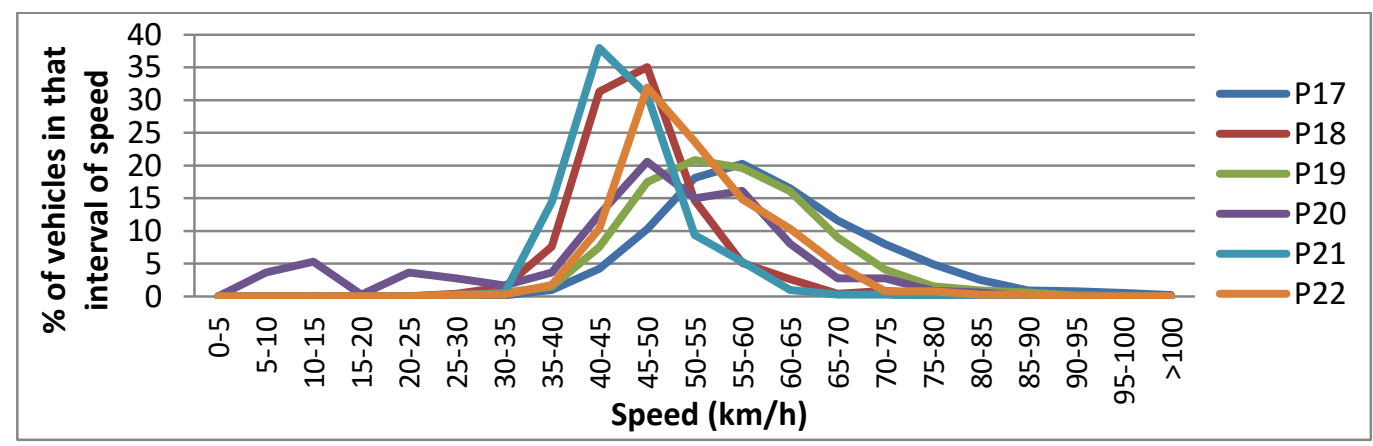

Fig. 17 - Speed profile at zones 5 and 6

This work is licensed under a Creative Commons Attribution-NonCommercial-NoDerivatives 4.0 International License (CC BY-NCND 4.0). 


\subsection{Radar speed camera at zones 3 and 4}

In zone 5 the four lanes street section P18 between the two Radar speed camera sign (RSCs50) presents a $V_{85}$ speed $15-20 \mathrm{~km} / \mathrm{h}$ lower than the speed at the street sections P17 and P19. In zone 6 the $\mathrm{V}_{85}$ speed at P21 is $10 \mathrm{~km} / \mathrm{h}$ lower than the speed at P20 and P22. The fig. 17 shows how the radar speed cameras are working only as punctual traffic calming measures. This measures should be combined with other traffic calming actions to increase the effectiveness of speed decreasing.

\section{CONCLUSIONS}

The traffic calming measures that got the best improvements on lowering the speed were the raised crosswalk and the lane narrowing. The radar speed camera only works as a punctual traffic calming measure. The radar speed camera and the radar speed warning signs need other traffic calming measures before and after them to keep that street calm. Intersection regulated by a roundabout or by a traffic light can be used as traffic calming measures but normal crosswalk and pedestrian pushbuttons signals don't reduce the speed by themselves. Best results were obtained when more than one traffic calming measures were used along the street and the distance between them is not too long.

\section{REFERENCES}

BONANOMI, L (1990). Le temps des rues. Ver um Manuel aménagement de léspace rue. DGT (2015a). Road Safety Data Spain 2014. Dirección General de Tráfico (DGT), Ministerio del Interior, Spanish Government. Madrid. España.

DGT (2015b). Las Principales Cifras de la Siniestralidad Vial. España 2008-2014. Dirección General de Tráfico (DGT), Ministerio del Interior, Spanish Government. Madrid. España. DGT (2016). Balance de Seguridad Vial 2015. Dirección General de Tráfico (DGT), Ministerio del Interior, Spanish Government. Madrid. España.

EC. (2010). Towards a European road safety area: policy orientations on road safety 20112020. COM (2010) 389 final. European Commission (EC). Brussels. Bélgica.

EWING, R. (1999) Traffic Calming: State of the practice. Institute of Transportation Engineering, Washington D. C. Estados Unidos de América.

LITMAN, T. (1999) Traffic Calming Benefits, Costs and Equity Impacts. Victorian Transport Policy Institute, Victoria. Canadá.

LOCKWOOD, I. (1997) ITE Traffic Calming Definition, ITE Journal, Institute of Transportation Engineering July 1997, pp. 22-25.

MFOM (2008). Instrucción Técnica para la instalación de reductores de velocidad y bandas transversales de alerta en carreteras (Orden FOM/3053/2008). Ministerio de Fomento. , Spanish Government. Madrid. España.

PAU, M. and ANGIUS, S. (2001). Do speed bumps really decrease traffic speed? An Italian experience. Accident Analysis and Prevention, 33, pp. 585-597. 